\title{
Tailings storage facility landform evolution modelling
}

\author{
H Thomson SRK Consulting (Australasia) Pty Ltd, Australia \\ L Chandler AEthos Consulting, Australia
}

\begin{abstract}
Landform evolution models (LEMS) are used to estimate potential surface water runoff and predict resulting erosion and deposition processes on a landform scale. When applied to mining landforms, LEM erosion predictions can be used to inform closure planning and to predict post-closure performance. The requirement to conduct long-term landform evolution modelling is an increasingly common regulatory condition imposed on new mining projects.
\end{abstract}

The use of LEMs to simulate the post-closure evolution of water-shedding mining landforms such as waste rock dumps is well documented. However, tailings storage facilities (TSFs) are unique landforms. TSFs often have contributing upstream catchments, long and flat (tailings beach) slopes, consist of spatially variable material types, and can be closed systems (i.e. do not release water). These factors all need to be accounted for when using an LEM to simulate a TSF.

This paper presents an approach to landform evolution modelling for TSFs, including an Australian case study using the CAESAR-LISFLOOD model to simulate the evolution of a valley-fill TSF over a 1,000-year post-closure period. Recent developments in the CAESAR-LISFLOOD LEM have significantly improved the run speed and computational efficiency of the model. The approach presented in this paper takes advantage of these improvements, incorporating the use of digital elevation models with different spatial resolutions and long-term simulations using 1,000 years of sub-daily rainfall data.

The CAESAR-LISFLOOD model can simulate the various material types present at the surface of a TSF landform including tailings, cover material, natural soils in the surrounding catchment, and embankment construction materials. As such, landform evolution modelling for valley-fill TSFs can be used to assess the extent to which erosion can compromise the water storage capacity of the closed TSF. The results of the example presented indicate that the water storage capacity of the TSF will be progressively reduced due to the sediments that are eroded and deposited within the pond area; however, not to the extent that could result in water (and potentially entrained tailings) being discharged to the environment. The results of TSF LEM could also be used to identify areas where design options could improve long-term TSF erosional stability, develop recommendations for model calibration and verification, and to assess whether erosion could result in loss of containment.

Keywords: tailings storage facility, landform evolution modelling, erosion, CAESAR-LISFLOOD

\section{Introduction}

There are several different methods that can be used to estimate soil erosion, ranging in complexity from simple mathematical equations (such as RUSLE), hillslope models (such as WEPP) to landform evolution models (LEMs) (such as SIBERIA and CAESAR-LISFLOOD). The requirement to conduct long-term landform evolution modelling is an increasingly common regulatory condition imposed on new mining projects.

LEMs are used to estimate potential surface water runoff and predict resulting erosion and deposition processes on a landform scale, considering the changes in the surface over time. LEM erosion predictions can be used to inform closure planning and to predict post-closure performance of mining landforms such as waste rock dumps and tailings storage facilities (TSFs). 
The use of LEMs to simulate the post-closure evolution of water-shedding mining landforms, such as waste rock dumps, is well documented. However, TSFs are unique landforms which often have contributing upstream catchments, long and flat tailings beach slopes, consist of spatially variable material types, and can be closed systems (i.e. do not release water). These factors all need to be accounted for when using an LEM to simulate a TSF.

This paper presents an approach to landform evolution modelling for TSFs, including an Australian case study using the CAESAR-LISFLOOD model to simulate the evolution of a valley-fill TSF over a 1,000-year post-closure period.

\section{Methodology}

\section{$2.1 \quad$ Objectives}

The main objectives of landform evolution modelling are to estimate potential surface water runoff and predict resulting erosion and deposition processes. When applied to a TSF, multiple elements can be considered such as the tailings beach, catchment, cover, embankment, and/ or spillway. As such, an LEM can be used to generate answers for the following questions related to the post-closure performance of a TSF:

- To what extent will the eroded sediments (from the external catchment and/ or the tailings beach) reduce the water storage capacity of the closed TSF?

- Will tailings solids eroded from the beach be discharged to the environment? If so, where will the tailings be deposited?

- What are the capping requirements to minimise erosion of the tailings beach?

- Could erosion of the embankment or spillway cause undercutting or failure?

The outcomes of such predictions can be used to compare and evaluate closure options or to identify areas where long-term landform performance can be improved.

\subsection{Approach}

There are three components of landform evolution modelling that are critical to modelling a TSF: the material representation, spatial resolution, and rainfall pattern.

There are typically various materials present at the surface of a TSF landform such as tailings, cover material, natural soils in the surrounding catchment, and construction materials. These materials have different characteristics including erodibility, surface roughness, infiltration, and weathering. The LEM must be able to adequately represent these different characteristics, as well as the spatial distribution of the materials.

The selected spatial resolution of a model must be fine enough to adequately represent the features of the terrain. For a TSF, this can include relatively small features such as embankment benches and slopes, diversion channels and spillway chutes, as well as larger features such as the tailings beach and contributing catchment. The spatial resolution of the model must be carefully selected to include all features of interest, while also considering computational demand. As demonstrated in the case study (Section 3), multiple models with different spatial resolutions may be the most effective solution.

As erosion is predominantly controlled by the periods of highest intensity rainfall (Baartman et al. 2012; Moliere et al. 2002; Vaezi et al. 2018; Ziadat \& Taimeh 2013), the selection of rainfall pattern applied to the LEM is critical. The rainfall pattern must be selected to address the objectives of the study and must have a sufficiently small temporal resolution to include periods of high intensity. For example, a deterministic model of a short-term, extreme storm event may be useful to verify an LEM with a recorded event, while multiple realisations of a long-term, stochastic model may be useful to predict the post-closure performance of a TSF.

CAESAR-LISFLOOD is one of the LEMs most commonly used in the Australian mining environment. The CAESAR-LISFLOOD model (Coulthard et al. 2013) combines a topographic evolution model (CAESAR) with a 
high-quality hydraulic model (LISFLOOD). The CAESAR-LISFLOOD model is suitable to use for landform evolution modelling of TSFs due to the following features:

- The model can be used over range of spatial and temporal scales.

- The outputs are both graphical and numerical.

- The main input the model uses to characterise the materials is the grain size distribution, which is a measurable and well-understood parameter.

- The material properties are spatially variable.

- Different rainfall datasets can be modelled (i.e. single storm events as well as long-term simulations) at different time intervals. This provides a means of exploring climate change implications as part of landform evolution modelling.

- The model has been validated in the Australian mining climate using purpose-built erosion plots located on a trial rehabilitated landform at the Ranger Uranium Mine (Lowry et al. 2015).

Furthermore, the model is open source and is updated regularly. The main perceived limitation of the CAESAR model is that the model is computationally intensive which can result in long model run times. However, technological advances resulting in improved computing performance, in conjunction with developments in the model (Coulthard et al. 2013), have resulted in the modelling being faster and computationally more efficient.

\section{Case study}

This paper presents an Australian case study using the CAESAR-LISFLOOD model (Coulthard et al. 2013) to simulate the evolution of a valley-fill TSF over a 1,000-year post-closure period. The layout of the TSF is shown in Figure 1 and features a contributing catchment, tailings beach, and containment embankment. The closure plan is that the TSF will remain a closed system and will not discharge water to the environment. Surface runoff will be collected in the low area of the tailings beach and will eventually evaporate or infiltrate. An emergency spillway will be provided to prevent overtopping of the embankment during extreme events.

The results of the study were used to assess whether a cover layer would be required to reduce erosion of the tailings beach at closure. Typical beach closure methodologies include over-dumping with waste rock and capping with various engineered covers to limit infiltration and/or provide growth medium for post-mining vegetation. However, for the site-specific conditions (arid climate), revegetation of the site-other than to the current low vegetation density-is unlikely to be successful. There are also dry salt lake analogues in the area, which would suggest that an uncapped facility may be a more suitable analogue to the closed TSF. Separate studies were undertaken to assess the other impacts of leaving the tailings beach uncapped, such as wind erosion and aesthetic considerations. These studies indicate that an engineered cover layer will likely not be required, however, a nominal layer of non-reactive material may be required to limit fauna access to the tailings surface.

The LEM was used to determine whether capping would be required from the perspective of managing tailings movement into the environment as the result of surface water erosion. The key objectives of the landform evolution modelling in this example include assessing whether water erosion of land surfaces could have the following effects:

- Compromise the water storage capacity of the closed TSF (causing water to be discharged via the spillway).

- Result in entrainment of tailings in water discharged to the environment.

- Result in embankment failure or undercutting of the embankment.

The CAESAR-LISFLOOD model was used for this study as it accommodates the factors described in Section 2.2 that are critical to modelling a TSF such as allowing spatially variable materials, as well as the ability to use 
different rainfall datasets. Furthermore, recent developments in the model (Coulthard et al. 2013) have significantly improved the run speed and computational efficiency of the model, achieving a smaller spatial resolution without sacrificing model run times.
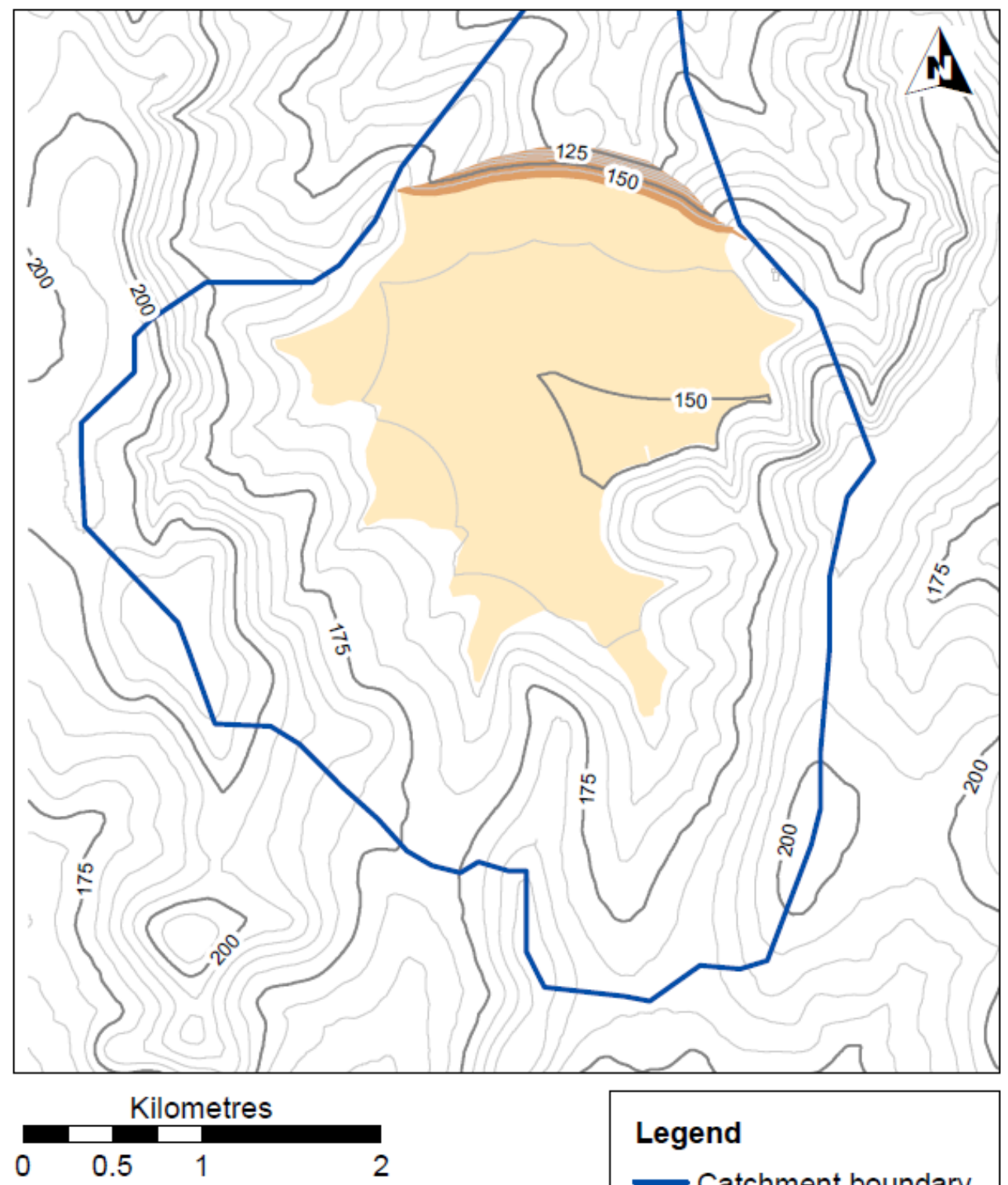

\section{Legend \\ Catchment boundary Tailings \\ Embankment}

Figure 1 Tailings storage facility layout

\subsection{Model inputs}

\subsubsection{Digital elevation models}

The surface topography is represented in the CAESAR-LISFLOOD model by a digital elevation model (DEM). The DEM extended upstream of the TSF to incorporate the entire upstream catchment (approximately $1,500 \mathrm{ha}$ ), including the tailings beach and embankment (approximately $510 \mathrm{ha}$ ) and extended approximately $1 \mathrm{~km}$ downstream of the TSF embankment.

Table 1 details the separate models prepared with different spatial resolutions to assess the embankment only versus the entire TSF and catchment. The detailed embankment models had finer grids to ensure 
adequate representation of the features of the embankment, such as the crest and downstream benches. Smaller grid size models were not run for the whole of the TSF because to do so would have resulted in excessively long modelling run times without materially improving model outcomes.

Table 1 Digital elevation model (DEM) grid sizes and model run times

\begin{tabular}{lllll}
\hline Simulation time & Area & DEM area & DEM grid size & Model run time $^{1}$ \\
\hline \multirow{2}{*}{ 24 hours } & Embankment detail & $1.2 \mathrm{~km}^{2}$ & $3 \mathrm{~m}$ & 1-18 hours \\
& TSF and catchment & $33.5 \mathrm{~km}^{2}$ & $8 \mathrm{~m}$ & $1-18$ hours \\
1,000 years & Embankment detail & $1.2 \mathrm{~km}^{2}$ & $8 \mathrm{~m}$ & 23 hours \\
& TSF and catchment & $33.5 \mathrm{~km}^{2}$ & $20 \mathrm{~m}$ & 7 days \\
\hline
\end{tabular}

${ }^{1}$ Model run on a HyperV virtual machine with 24 virtual CPUs and 48GB RAM running Windows 7 sitting on a physical host with dual socket Xeon E5-2660 v3's @ 2.60GHz and 256GB of 2133Mhz RAM total

A bedrock surface can be specified in the CAESAR-LISFLOOD model to represent a layer below which erosion cannot occur. In the absence of geotechnical investigation, the bedrock surface was developed assuming a constant $3.5 \mathrm{~m}$ thickness of colluvial and residual clay beneath the pre-development surface. However, it is expected that bedrock is likely to be shallower in areas of the catchment, particularly where bedrock appears to be exposed in the watercourses. As such, the LEM is likely to predict more erosion of the natural catchment than would actually occur over the long-term, particularly around the existing natural gullies where the amount of material available for erosion is less than has been represented in the model. If required, the bedrock surface could be refined with the outcomes of a geotechnical investigation.

\subsubsection{Rainfall}

The TSF is located in an arid region, with no distinct wet or dry seasons, and with mean annual rainfall and evaporation of $182 \mathrm{~mm}$ and 3,120 $\mathrm{mm}$, respectively. The site experiences rainfall on and average of 2 to 6 days per month.

A 1,000-year synthetic precipitation record was generated using the Hyetos model (Koutsoyiannis \& Onof 2001) implemented in R programming language, under the name HyetosR (Kossieris et al. 2012). The objective was to generate a synthetic hourly rainfall series for a 1,000-year period which was fully consistent with the available 128-year daily rainfall record and simultaneously statistically consistent with the hourly rainfall series (aggregated from a 22-year record of half-hourly data).

One realisation of the 1,000-year rainfall series generated is shown in Figure 2. The mean, variance, and proportion dry of the synthetic dataset have been computed and compared with historical values, as shown in Table 2. The synthetic series is shown to satisfactorily reproduce the key statistics of the dataset for the 1 , 24 , and $48 \mathrm{hr}$ periods.

The frequency analysis of extreme events compared to the historical dataset is shown in Figure 3 . The synthetic series produces slightly lower rainfall depths for the frequent events, but larger depths for the rare events. This is considered conservative as the periods of higher intensity (rare events) are likely to control the results of the modelling (Baartman et al. 2012; Moliere et al. 2002; Vaezi et al. 2018; Ziadat \& Taimeh 2013). 


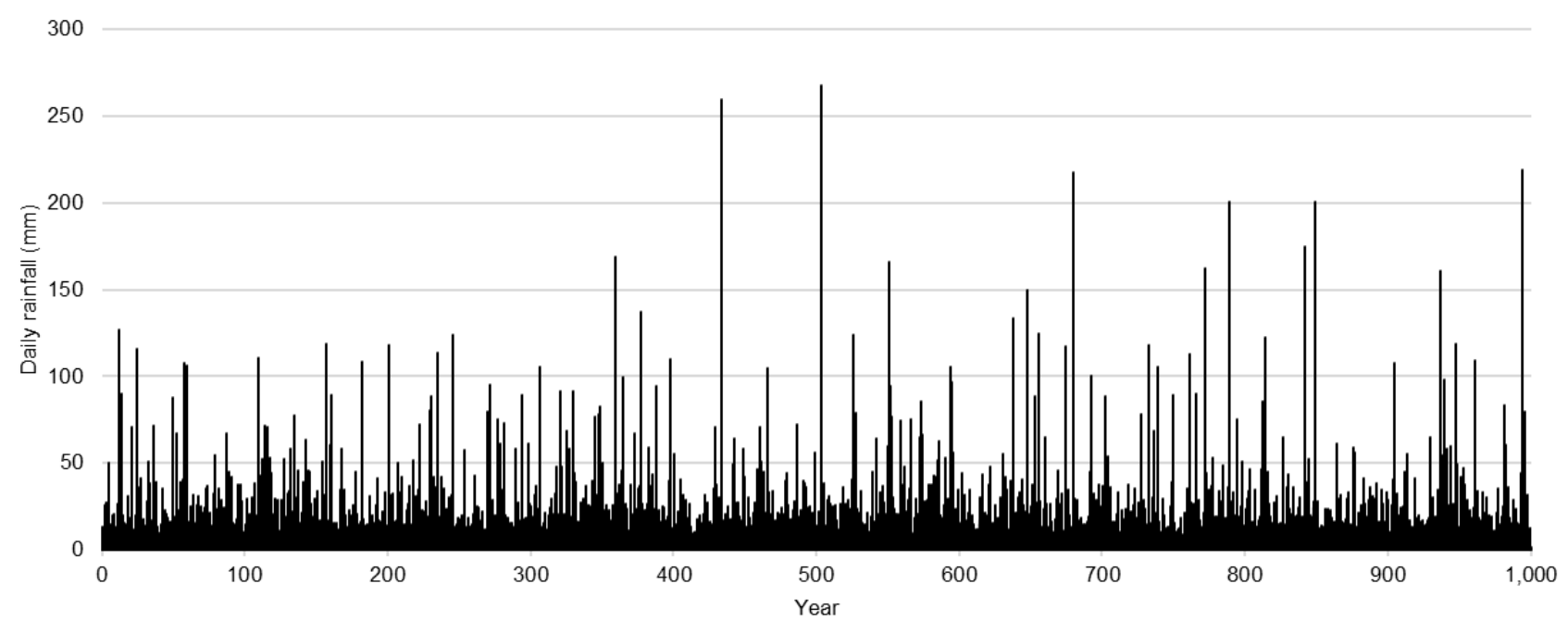

Figure 2 Synthetic 1,000 year rainfall series

Table 2 Rainfall series statistics

\begin{tabular}{lllllll}
\hline & Hourly & & 24-hourly & & 48-hourly \\
& Historical & Synthetic & Historical & Synthetic & Historical & Synthetic \\
\hline Mean $(\mathrm{mm})$ & 0.02 & 0.02 & 0.46 & 0.48 & 0.92 & 0.97 \\
Variance $(\mathrm{mm})$ & 0.15 & 0.18 & 7.3 & 7.5 & 17.6 & 15.6 \\
Proportion dry & $98.2 \%$ & $98.8 \%$ & $86.6 \%$ & $76.6 \%$ & $78.8 \%$ & $58.7 \%$ \\
Maximum $(\mathrm{mm})$ & 63 & 118 & 138 & 267 & 149 & 463 \\
\hline
\end{tabular}

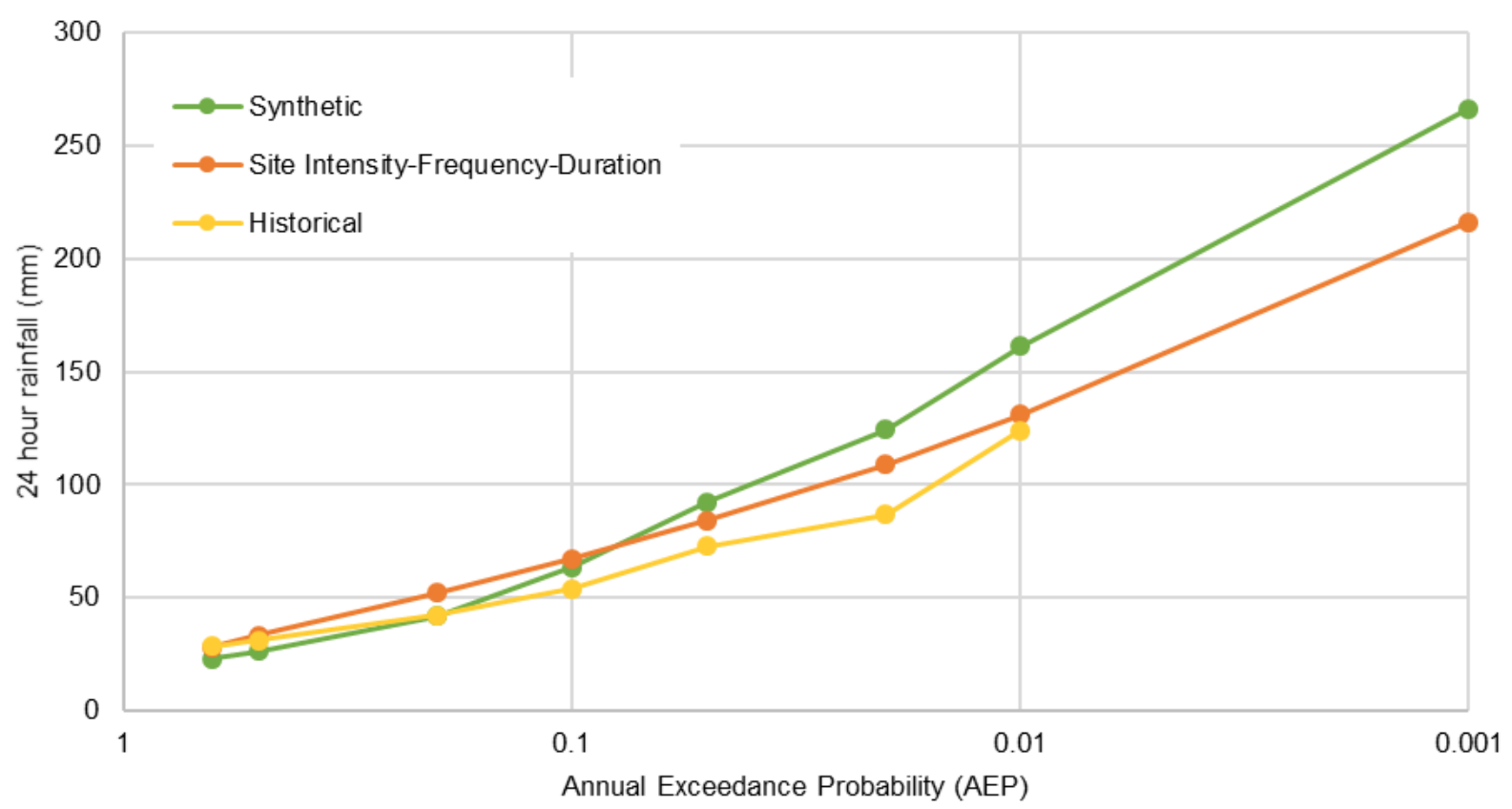

Figure 3 Rainfall 24-hour event frequency analysis 


\subsubsection{Soil properties}

The distribution of surface material types across the landform was modelled using a spatially variable particle size distribution, with corresponding regions shown in Figure 4. The models assumed that the tailings beach is exposed and no capping layer is in place.

The various material zones are represented in the CAESAR-LISFLOOD model by a grain size distribution, with up to nine grain size classes. The adopted grain size distributions are shown in Figure 5 . Weathering, i.e. a decrease in material particle size over time, was not simulated in the modelling but can potentially be simulated in CAESAR-LISFLOOD (note this is an experimental feature) and may need to be considered where materials are likely to be susceptible to weathering, as demonstrated in the study by Lowry et al. (2015).

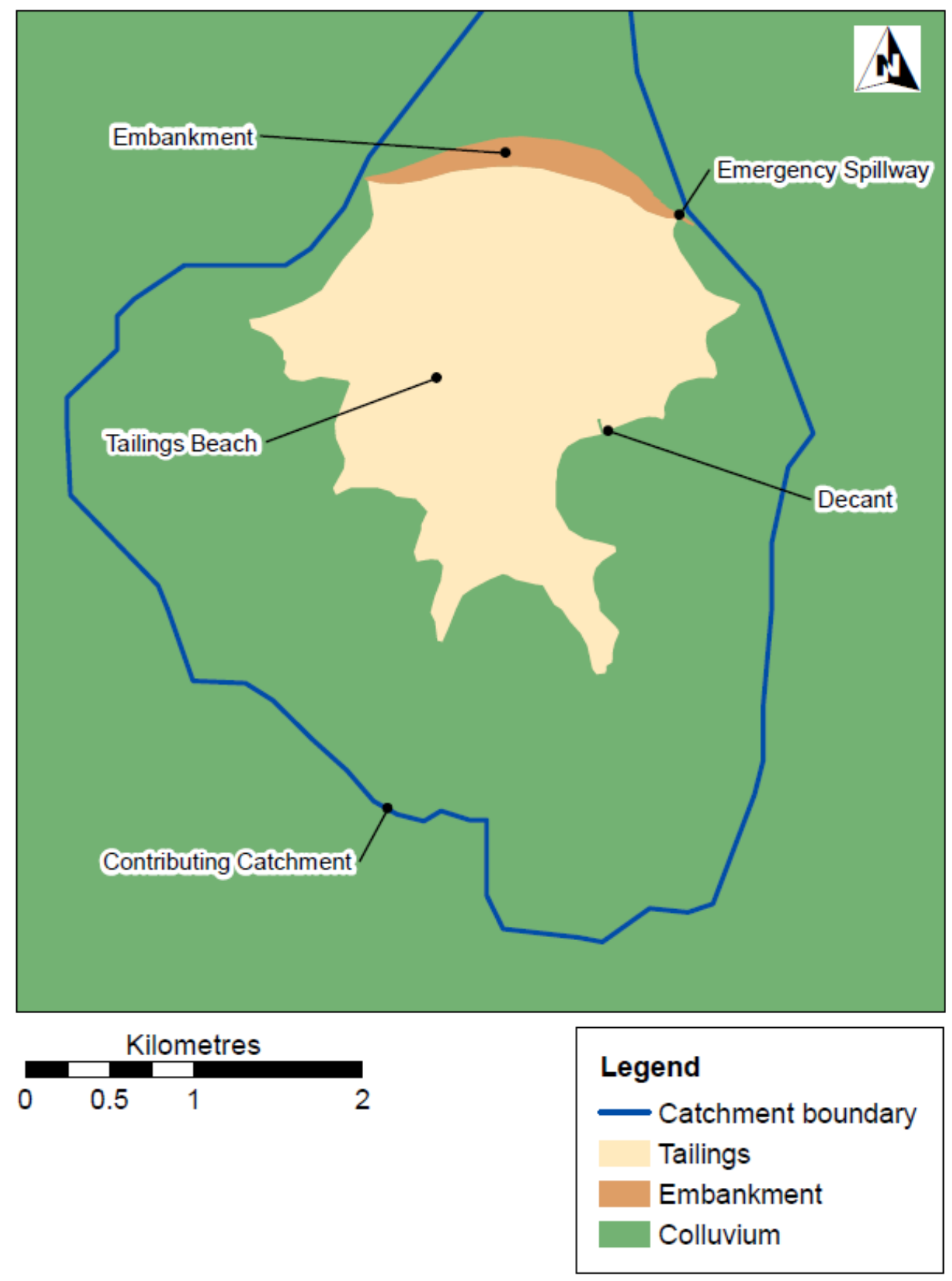

Figure 4 Spatial distribution of materials 


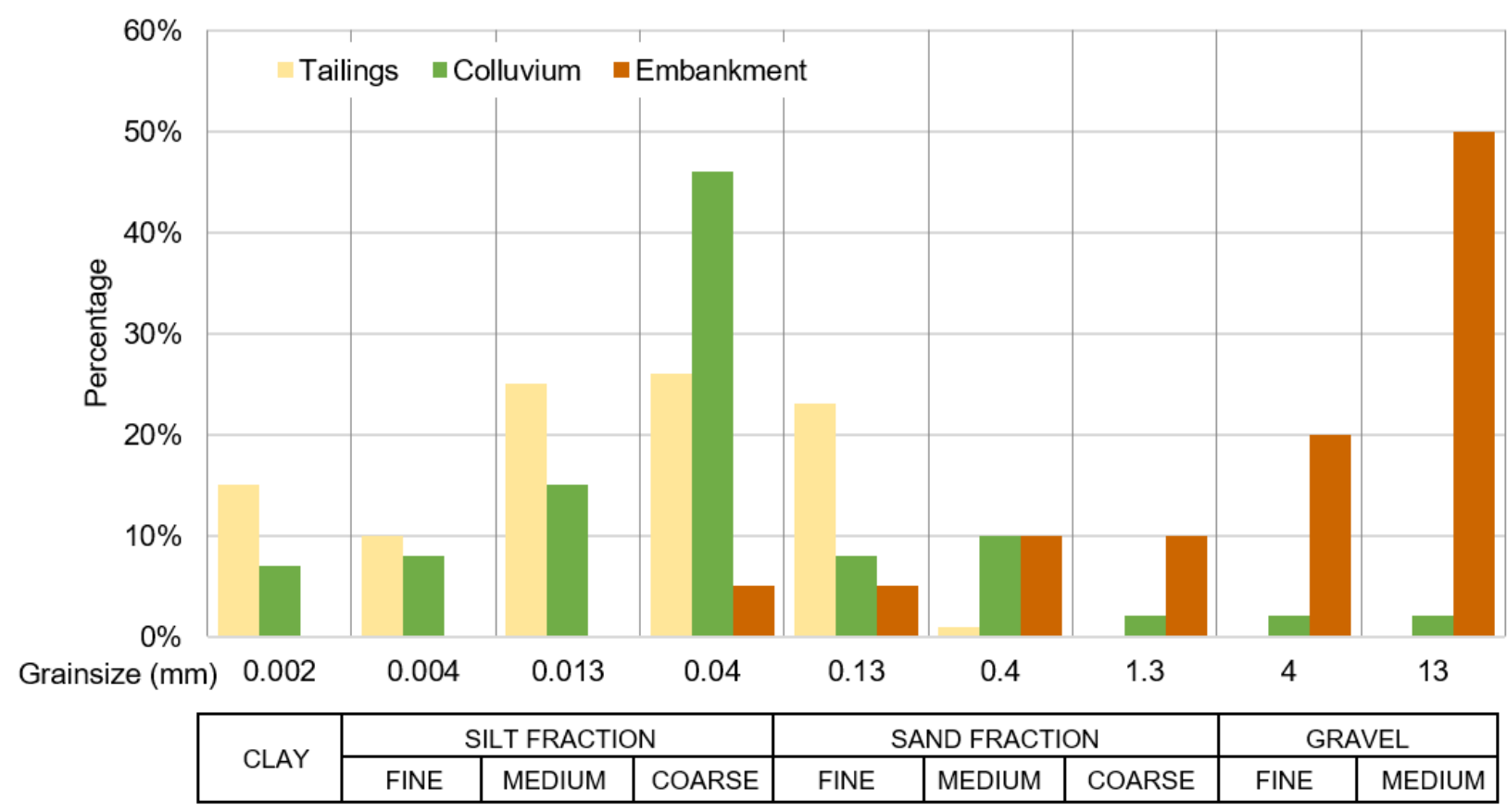

Figure 5 Grain size classifications

\subsection{Results}

The results of the 1,000-year simulation are shown in Figure 6 in the form of graphical outputs which illustrate the change in elevation across the landform, indicating areas of erosion and deposition.

Erosion of the contributing catchment is concentrated in existing gullies, as expected. The LEM is likely to predict more erosion of the natural catchment than would actually occur over the long-term, as the colluvium layer is thinner than the constant $3.5 \mathrm{~m}$ assumed in the model around the existing natural gullies, thereby limiting the amount of material actually available for erosion. The modelled long-term sediment yield from the upstream catchment is in the order of $3 \mathrm{t} / \mathrm{ha} / \mathrm{yr}(0.2 \mathrm{~m}$ average erosion depth), which is consistent with published values of natural erosion rates for rangeland soils in the project area (Lu et al. 2003). All sediments eroded from the upstream catchment are deposited on the tailings beach.

Although the modelling is considered conservative, the predicted erosion is low due to the arid climate and location of the TSF in the upper reaches of the catchment (small contributing catchment). Furthermore, the tailings deposition plan is designed to keep the pond away from the embankment. This is optimal in terms of minimising erosion as it provides a large storage volume at closure (reducing the risk of embankment overtopping) and reduces the length of the flow path over the tailings surface and resultant flow velocities/erosion.

Erosion gullies form within the uncovered tailings surface to a maximum depth of $3.7 \mathrm{~m}$ (these are maximum gully depths at the entry location from the upstream catchments onto the TSF surface). The pattern of erosion on the tailings surface is controlled by the tailings surface topography (deposition strategy) and location of flows being concentrated by the natural catchment. Eroded tailings are deposited entirely within the tailings basin, predominantly around the operational pond area toward the eastern side of the facility. No tailings were shown to discharge to the environment. As such, this indicates that no cover layer is required to prevent tailings movement into the environment as the result of surface water erosion.

The results of the 1,000-year detailed embankment simulation are shown in Figures 7 and 8 . The LEM indicates very little erosion of the embankment as there is no contributing upstream catchment: any surface water runoff is from direct precipitation on the embankment only. As shown in Figures 7 and 8, erosion is concentrated on the upper and intermediate crests, and eroded materials are deposited on the subsequent embankment bench, i.e. the benched surface is gradually flattened to a continuous slope. It should be noted 
that the model assumes that the embankment is constructed to the design surface and that the materials are homogeneous. As the surface materials can be varied spatially in the CAESAR-LISFLOOD model, the model could be used to assess and compare different design options such as using rock armour on localised areas of the embankment face.

Erosion is also concentrated to the natural materials at the downstream toe of the embankment where any runoff from the embankment flows along the toe and continues downstream. The area immediately downstream of the embankment may need to be armoured (or a lined channel constructed) to prevent undercutting of the embankment.
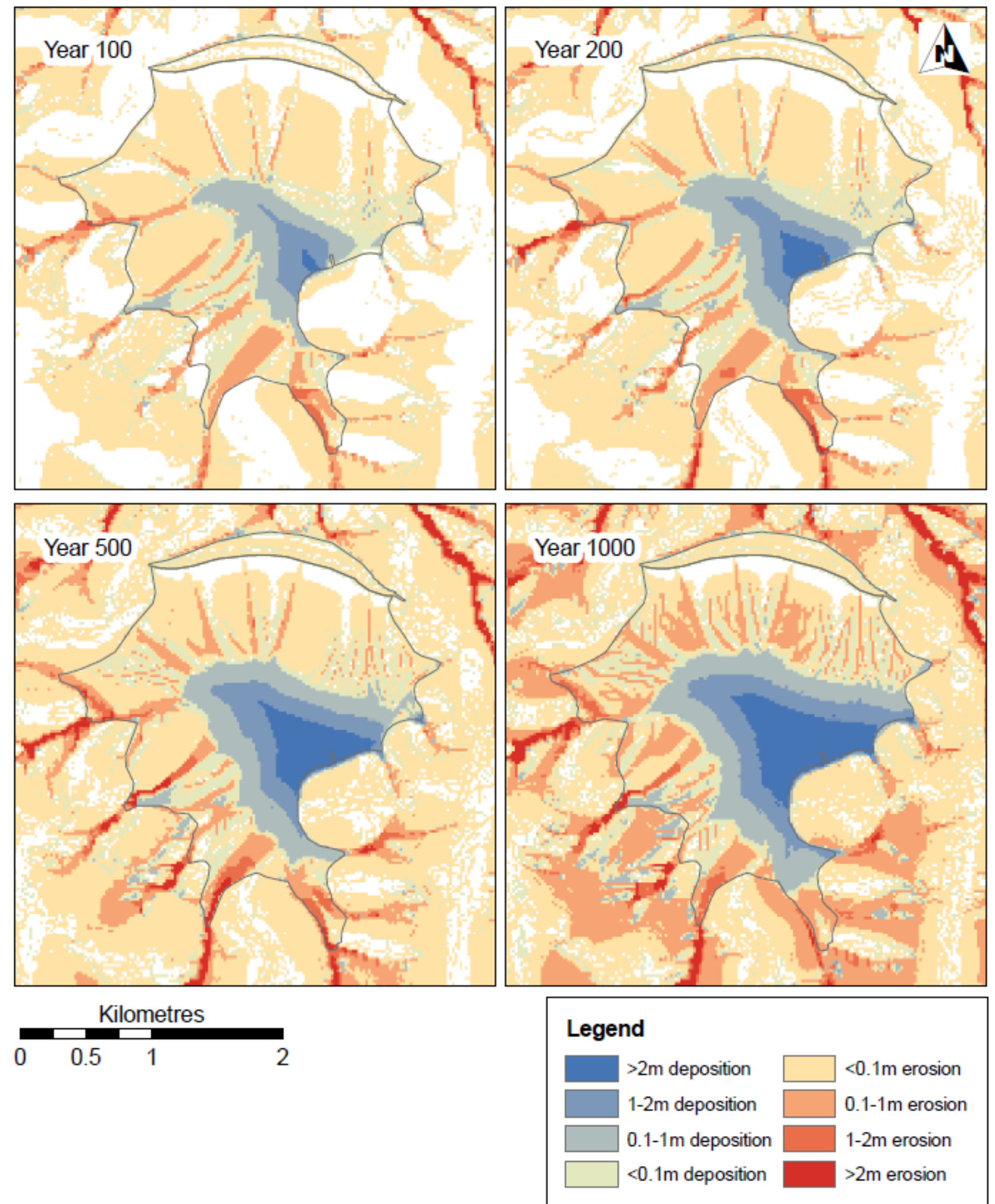

Figure 6 Tailing storage facilities post-closure landform evolution models results 

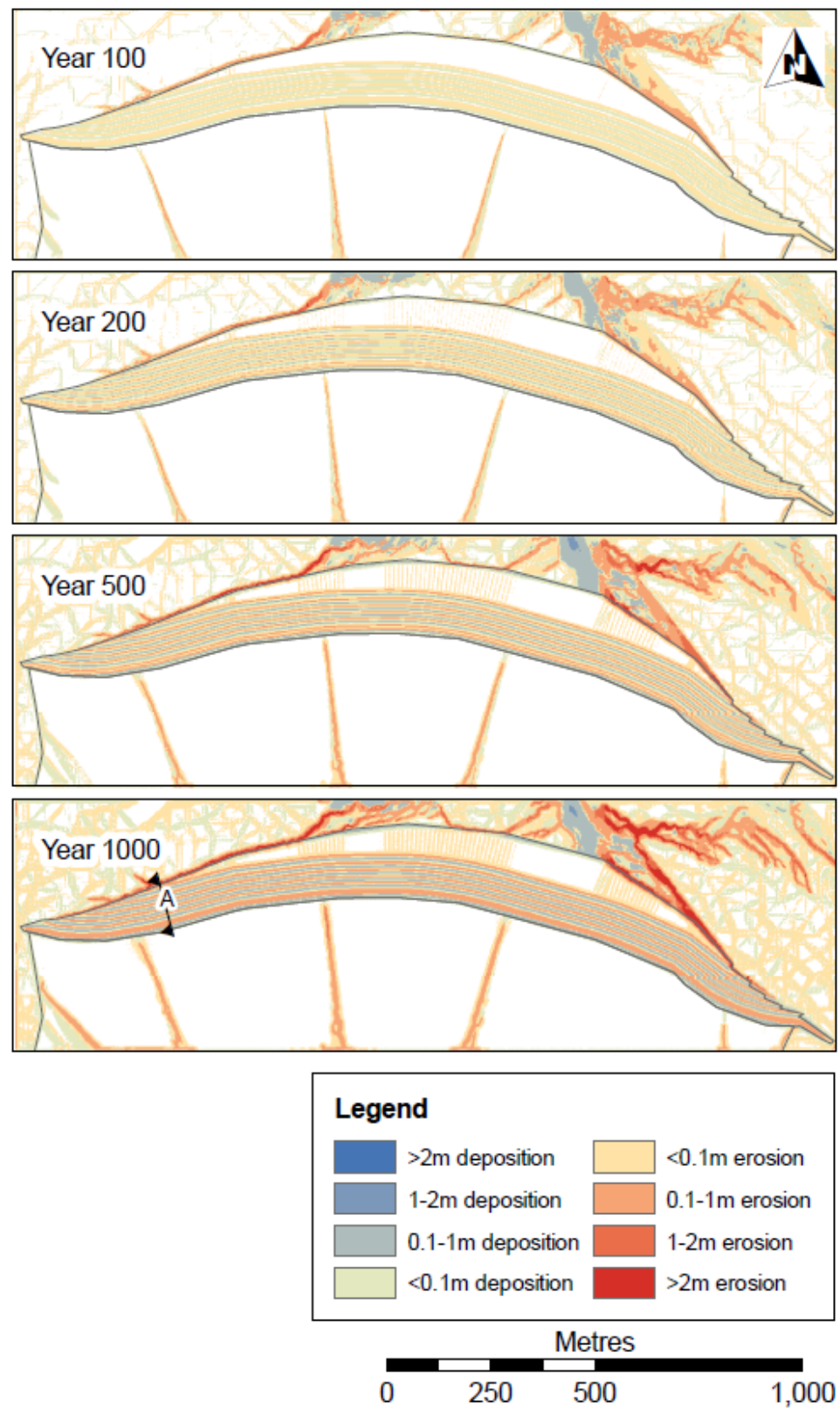

Figure 7 1,000-year detailed embankment model results

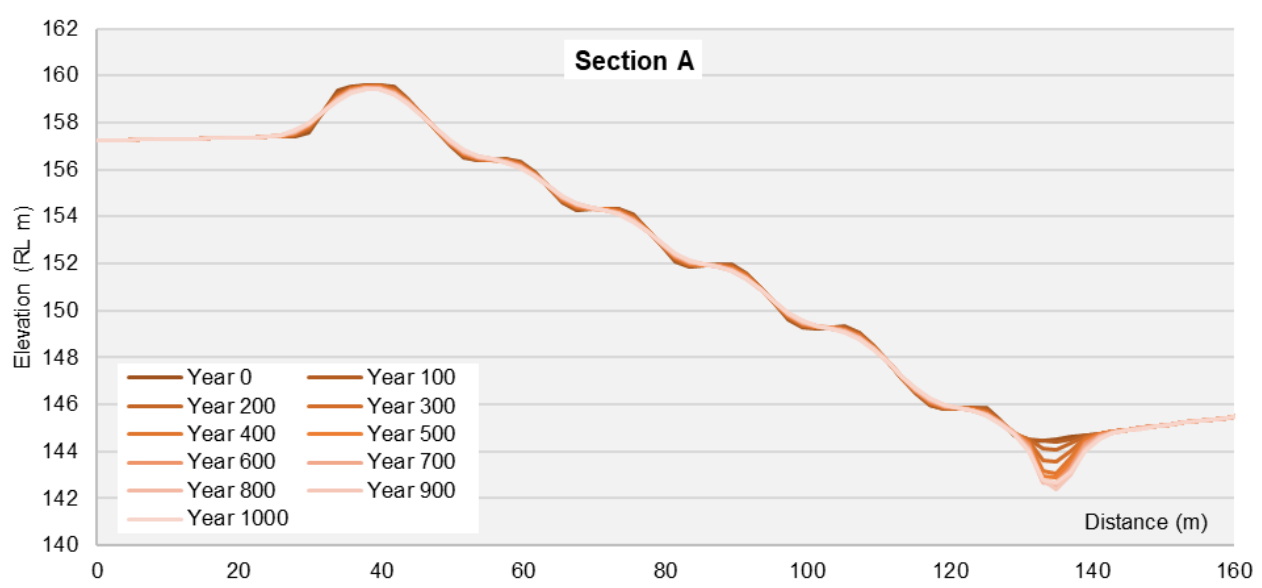

Figure 8 1,000-year detailed embankment model - Section A 


\section{$4 \quad$ Future work}

The following opportunities have been identified for future work that could improve TSF landform evolution modelling outcomes at the site represented in the case study:

- Model calibration: As for all models, the LEM should be calibrated with measured parameters. The hydrological model (i.e. runoff, evaporation, and seepage) could be calibrated using streamflow measurements and/ or an operational TSF water balance. The topographic evolution model could be calibrated using erosion field studies, including detailed morphometric surveys and measurement of runoff and sediment load from the downstream embankment surface and selected representative areas of quarantined tailings beach.

- Model verification: To facilitate model verification, periodic monitoring, including detailed morphometric surveys of the land surface, should be implemented to check elevation changes against model predictions, particularly after major rainfall events. Field-scale rainfall simulation and erosion testing on replicated field plots is recommended given the dry climate and predicted low erosion rates.

- Multiple realisations of rainfall data: The case study presented used a single realisation of the stochastic rainfall data. Multiple realisations of rainfall data could be applied, and the results compared to assess the impact of the sequence and intensity of rainfall.

- Bedrock surface: Geotechnical investigations could be undertaken to develop a subsurface profile over the upstream natural catchment indicating depth to bedrock. More accurate definition of the bedrock surface will improve the model predictions in the surrounding catchment.

- Tailings consolidation: The depth of tailings typically varies across a tailings deposit, particularly in a valley-fill TSF. As such, the final tailings beach surface will vary as the tailings deposit consolidates. Predictions of the consolidation behaviour of the deposit could be considered in the DEM to improve model predictions of surface water runoff and erosion/deposition over the tailings beach.

- Climate change: The impacts of climate change could be incorporated into the long-term synthetic precipitation record.

\section{Conclusion}

This paper presents an approach to landform evolution modelling for TSFs, highlighting three components of a LEM that are critical to modelling a TSF: the material representation, spatial resolution, and rainfall pattern.

The case study presented demonstrates how this approach can be used to predict the post-closure erosion and deposition processes of a TSF.

Key findings of the example presented include:

- The predicted erosion rates are low as the site has an arid climate and the TSF is located in the upper reaches of the catchment.

- Sediment is eroded from the natural catchment at an average long-term rate in the order of $3 \mathrm{t} / \mathrm{ha} / \mathrm{yr}$. This is largely concentrated in existing gullies, and eroded sediments are deposited on the tailings beach.

- The TSF is a closed catchment with a spillway provided for emergencies. Eroded tailings are deposited entirely within the tailings basin, predominantly around the operational pond area to the east of the facility. No tailings are shown to discharge to the environment.

- The water storage capacity of the TSF is progressively reduced due to the sediments that are eroded and deposited within the pond area. However, the TSF has enough available storage capacity at the end of the model duration to store the runoff from the design storm. 
These findings indicated that no cover layer would be required from the perspective of managing tailings movement into the environment as the result of surface water erosion (notwithstanding wind erosion or aesthetic considerations). The results of the LEM could also be used to develop recommendations for model calibration and verification.

Several opportunities have been identified for future work that could improve TSF landform evolution modelling outcomes.

\section{Acknowledgement}

The authors would like to thank Dave Luppnow, Rachel Thompson, and Ricky Wulfse for their contributions to this paper. The authors would also like to thank Professor Tom Coulthard for his excellent work on the CAESAR-LISFLOOD model.

\section{References}

Baartman, JEM, Jetten, VG, Ritsema, CJ \& de Vente, J 2012, 'Exploring effects of rainfall intensity and duration on soil erosion at the catchment scale using open LISEM: Prado catchment, SE Spain', Hydrological Process, vol. 26, pp. 1034-1049.

Coulthard, TJ, Neal, JC, Bates, PD, Ramirez, J, de Almeida, GAM \& Hancock, GR 2013, 'Integrating the LISFLOOD-FP 2D hydrodynamic model with the CAESAR model: implications for modelling landscape evolution', Earth Surface Processes Landforms, vol. 38, pp. 1897-1906.

Kossieris, P, Koutsoyiannis, D, Onof, C Tyralis, H \& Efstratiadis, A 2012, 'HyetosR: An R package for temporal stochastic simulation of rainfall at fine time scales', European Geosciences Union General Assembly 2012, Geophysical Research Abstracts, vol. 14, 11718.

Koutsoyiannis, D \& Onof, C 2001, 'Rainfall disaggregation using adjusting procedures on a Poisson cluster model', Journal of Hydrology, vol. 246, pp. 109-122.

Lowry, J, Saynor, M \& Erskine, W 2015, A Multi-year Assessment of Landform Evolution Model Predictions for the Ranger Trial Landform, Internal report 633, Australian Government, Department of the Environment and Energy.

Lu, H, Prosser, IP, Moran, CJ, Gallant, JC, Priestley, G \& Stevenson, JG 2003, 'Predicting sheetwash and rill erosion over the Australian continent', Australian Journal of Soil Research, vol. 41, pp. 1037-1062.

Moliere, DR, Evans, KG, Willgoose, GR \& Saynor, MJ, 2002, Temporal trends in erosion and hydrology for a post-mining landform at Ranger Mine. Northern Territory, Supervising Scientist Report 165, Australian Government, Department of the Environment and Energy.

Vaezi, AR, Eslami, SF \& Keesstra, S 2018, 'Interrill erodibility in relation to aggregate size class in a semi-arid soil under simulated rainfalls', Catena, vol. 167, pp. $385-398$.

Ziadat, FM \& Taimeh, AY 2013, 'Effect of rainfall intensity, slope, land use and antecedent soil moisture on soil erosion in an arid environment', Land Degradation \& Development, vol. 24, pp. 582-590. 